medicine can be computerized or not, do we want to computerize it? Sooner or later mankind must ask what it is going to do with all the human energy and time that the computers are beginning to release or make redundant. - I am, etc.,

W. C. WATSON

Department of Medicine and Gastrointestinal Unit, Victoria Hospital,

Ontario, Canada

\section{Child Health in a Changing Community}

SIR,-I read Professor S. D. M. Court's lecture with great interest (17 April, p. 125). It is indeed a masterly survey of the problem.

However, in his discussion of the partners in the team needed for a rising standard of child health he does not mention child health doctors in the clinical field employed by local authorities. Has he perhaps included them as paediatric specialists? With their knowledge of developmental paediatrics they are an important factor in seeing that the young handicapped child-from any cause-is able to fulfil his potential.-I am, etc.,

Muriel J. BRayshay President, Maternal and Child Health Group,
Society of Medical Officers of Health Manchester 23

\section{Health of Young People}

SIR,-Perhaps it is significant that in the same issue of the B.M.F. we have the stimulating article by Dr. Ronald Gibson "The Satchel and the Shining Morning Face" (5 June, p. 549) and the important letter by Dr. D. Hooker (5 June, p. 585) on abortions and legal and medical ethics. Could it be that at last the B.M.A. is becoming concerned about the behaviour of young people? There has always been interest in antenatal care, infant welfare, school health service, and care of young people at work. Can we at last turn our attentions to the effect on the health of young people by the increasing trivialization and commercialization of sex? If health education is to mean anything to the young it must provide the sort of information which can be understood. This must be scientific and strictly accurate. The recent report on the dangers of smoking is a good example.

The medical profession should be in the forefront of any campaign to raise the health of the nation. In the near future there will be an opportunity for those concerned about these problems to show their interest by action.-I am, etc.,

London N.W.6

STANLEy ElLison

\section{Failure to Continue Education}

SIR,-In an analysis ${ }^{1}$ of the response of 99 general practitioners to a programme of continuing education we found that 64 of them attended three or more local sessions during the 13 months of the study and 35 attended fewer than three. We thought we should try to find out how we could make our programme more attractive.

Thirty-four of the 35 are still in practice, and each was asked to complete a question- naire designed to find out what he thought about our postgraduate programme and what sort of meeting he would prefer. Thirty-two of the 34 did so. Those who had attended meetings elsewhere were asked their reasons for doing so, and what courses they had attended. Information about years since graduation and number in partnership was available for the 34 doctors (group 1) and for the 64 (group 2) who had attended three or more sessions.

The Figure shows the distribution of the 34 doctors in terms of years since graduation (hatched) set against that of the whole group. The figures in the hatched areas give the percentage of the total number of doctors in each column who attended fewer than three sessions. Sixteen $(47 \%)$ doctors in group 1 worked single-handed or in twoman practices compared with 20 (31\%) doctors in group 2, and $16(47 \%)$ in group 1 lived more than five miles $(8 \mathrm{~km})$ from the postgraduate centre compared with 23 $\left(36^{\circ} \%\right.$ ) in group 2 . The reason given for poor attendance by 15 was that the time was unsuitable. Most general practitioners living more than five miles $(8 \mathrm{~km})$ from the centre found lunch-time meetings difficult. Five stated that the subjects were sometimes irrelevant to general practice, and several commented that they were hospital orientated. Of the $18(56 \%)$ who attended approved meetings elsewhere 11 chose general subjects, five cardiology, four obstetrics, four psychiatry, three family planning, three management, and one each diabetes, forensic medicine, medical hypnosis, paediatrics, rheumatology, teaching, and the social aspects of general practice. Some said they attended meetings elsewhere to meet

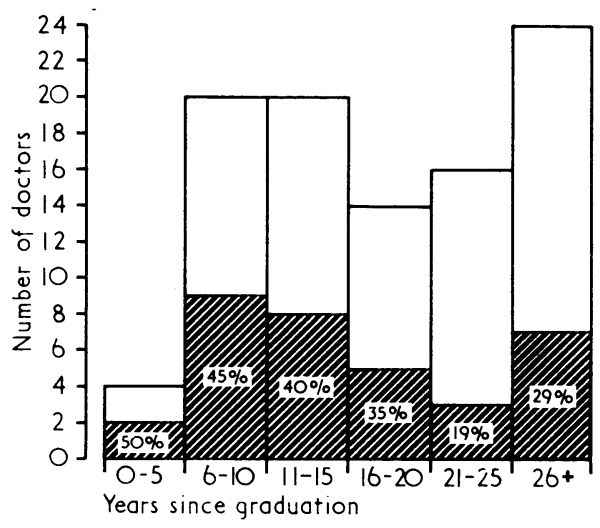

different people with different ideas. Seven held clinical posts in geriatrics, two in psychiatry, and one in anaesthetics. Of the 14 doctors in group 1 who did not attend meetings elsewhere eight ranked formal lectures first in their order of preference of type of meetings.

Contrary to our expectations the number of general practitioners attending more than three sessions increased with age, and this probably reflects the financial incentive inherent in seniority awards, which are payable only after 15 years. If meetings provide opportunities for learning it is no less important to offer incentives to recently qualified doctors, because it is easier to keep abreast of knowledge than to regain lost ground. Despite preference expressed for formal lectures we think they are of limited educational value. Meetings which encourage previous study and participation have been popular, ${ }^{1}$ and we are unwilling to change our policy. Some factors are beyond our control, but we shall try to encourage meetings at the periphery for those who find it difficult to come to our main centre and to promote as wide a variety of meetings as possible. We think incentives, financial or otherwise, might encourage younger doctors to attend. There will always be some who do not wish to come to meetings, but the onus is on the organizers to attract as many as possible.-We are, etc.,

J. T. CORBETT

P. G. DalgLeish

C. P. ElliotT-BinNS

T. A. RICHARDS

E. D. SEVER

J. P. TOBY

Cripps Postgraduate Medical Centre,

Northampton

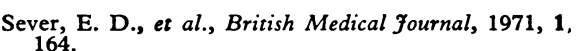

\section{False Economy}

SIR,-I have received the current comparison of drug costs chart from the Department of Health and Social Security. It deals with hypnotics (ECL 106/69 Serial No. 4/71).

I accept that "It is not suggested that the above products necessarily have the same pharmacological properties." However, I also accept that five of the six products listed are the subject of ignorant or wanton abuse across the whole population spectrum and that such abuse is often of iatrogenic aetiology.

Unfortunately, the one compound which, so far, has not been implicated in this way is revealed as the most expensive.

In view of the current addiction problems I think that this chart-which implies and suggests preference for barbiturates-should have been withdrawn from the series. It will not alter my desire to wean my patients off the barbiturates or methaqualone, and possibly to substitute with nitrazepam. I hope that others will not find themselves feeling guilty at prescribing the safest hypnotic.-I am, etc.,

London N.9

Christopher J. DAY

\section{Coroner's Power to Commit for Trial}

SIR,-It is unfortunate that your legal correspondent, in discussing the coroner's power to commit for trial (26 June, p. 781), should misrepresent both the sequence of events which led to Ian Spencer's committal and also the meaning of my own remarks on this subject to which he refers. He clearly does not understand the normal procedure in these cases and has failed to appreciate the coroner's dilemma.

The position is as follows. If the Director of Public Prosecutions does not wish to proceed against a suspect in a case of homicide he writes to the police authority concerned to that effect and asks to be informed if any further evidence is revealed at the inquest. The case has then to be brought to inquest, and if it appears to the coroner that the death has been brought about by murder, manslaughter, or infanticide he is obliged to empanel a jury (Coroners' Amendment Act, 1926 Section 13 ss. 2). If after hearing the evidence the jury decide that there is a prima facie case of some form of homicide they must say so and if they feel that there is prima facie evidence 
that any known person has caused the death they must name that person (Coroners' Act 1887 Section 4 ss. 3). Clearly, therefore, the coroner has no choice on these occasions but to proceed with his inquest. If, on the other hand, the D.P.P. decides that there is sufficient evidence to charge a suspect before the magistrates and the magistrates decide to dismiss the case because in their view there is not sufficient evidence, the coroner may resume the inquest if he wishes, but he very rarely does because he can issue an After Inquest Certificate without resuming and the case is then closed.

In the Spencer and Osborne cases the D.P.P. decided not to proceed and therefore the respective coroners were obliged to empanel juries. It is true that the Spencer case was brought before the magistrates for committal upon indictment but this was after the inquest and not before as your correspondent suggests.

To turn to my own previous observations on this topic, in speaking of "any previous decision not to proceed" I was referring to the decision of the D.P.P. and not to a dismissal by the bench which, as I have shown, for practical purposes closes the case. If your correspondent had been more familiar with the practical details of this aspect of criminal procedure my meaning would have been obvious to him. In this address I was appealing for the power of committal to be with-

\section{Functions of the G.M.C.}

SIR,-As a recently elected member of the G.M.C. it is a pleasure to read of the Hospital Jinior Staffs Group Council's decision to accept the Brynmor Jones Report (Supplement, 5 June, p. 125) and to recommend that no further action be taken to implement its recommendations until the G.M.C.'s functions have been reviewed.

Implementation of the report's recommendations can only delay a full review of the functions of the G.M.C. It was concern about the functions of the G.M.C. which lay at the heart of the recent conflict between the profession and the G.M.C. A full review of functions, constitution, and financing must be the first objective of the B.M.A. The most that the suggested compromise can do is buy temporary and uneasy peace within the profession and stave off the G.M.C.'s financial collapse for a few years.

The G.M.C. is becoming more expensive year by year without any evidence of a corresponding increase in efficiency or effectiveness, and there is little evidence to suggest that the increase in expenditure has been brought under control. The working party recommendations must lead to the creation of a much larger council and one which is likely to grow rapidly; the decision taken at the G.M.C.'s May meeting to recommend that two universities and two colleges should

be given representation on the council increases the size of a reformed G.M.C. by eight. There are at least another three colleges and universities waiting, giving minimum future expansion of six. As it grows I have no doubt that the G.M.C. will become flabbier, less efficient, and more expensive-scarcely what the profession wants Worse still the policy advocated by B.M.A Council could lead to the profession being humiliated as it goes to the Government asking for a 1974 Medical Bill to alter the functions and constitution of the G.M.C. befor the 1973 Bill altering the constitution alone had reached the Statute Book.

The Representatives gathered at Leicester would do well to ponder the shrewd lead given by the H.J.S. Group Council before following their leaders into an expensive and humiliating trap. If the Representative Body is wise enough to ask the Government for a public review of the functions, structure, and financing of the G.M.C. and recommends that the Brynmor Jones Report be buried (with honour), then I am prepared to help bail out the G.M.C. financially by paying the $£ 2$ retention fee, pending the outcome of the inquiry.-I am, etc.,

Boston, Lincs

Francis PigotT

\section{Hospital Staffing Structure}

SIR,-I note with regret that the profession has found itself unable to agree upon a staffing structure for doctors working in hospitals (Supplement, 12 June, p. 127). In these circumstances I find myself in agreement with the chairman of the Central Committee for Hospital Medical Services when he says that the possibility arises of taking the problem of medical staffing in hospitals "back to the drawing board."

I write now to enter a plea that, should this prove necessary, one proposal which should be considered is that which I advanced a year ago. ${ }^{1}$ I continue to think now, as I thought then, that these proposals would go a long way towards resolving our present difficulties, though it seems possible that in the light of the views of the General Medical Services Committee they would require in addition the creation of an entirely separate post, existing in parallel with the posts I proposed for general practitioners only. I am, etc.,

The London Hospital,

M. A. R. FREEMAN

London E.l 1 Freeman, M. A. R., British fournal of Hospital
Medicine, 1970, 3,761.

\section{Temporary Resident Fees}

SIR,-I wish to draw the attention of general practitioners, especially those looking after temporary residents, to E.C.L.26/71 issued by the Department of Health and Social Security in April 1971, which seeks to clarify para 37 of the Statement of Fees and Allowances regarding payment for temporary residents.

Should the recommendations of this E.C.L. be implemented I believe that many general practitioners will find a drastic reduction in their temporary resident payments for the next quarter. I submit the following observations.

At the inception of the N.H.S. the halfrate temporary resident fee applied to patients living in convalescent homes. Since then this has been expanded and it is now suggested that this fee should apply to any place with 10 or more persons, which would appear to cover everything from small guest houses to large camping sites.

The sudden influx of large numbers of holiday makers into caravan and chalet sites, which are often several miles away from main surgeries, sometimes demands setting up temporary surgery accommodation on these sites in order to cope with the volume of work. This is comparable to the arrangements made for our regular patients to be seen in main and branch surgeries. So far the Department of Health has not suggested that because we organize our regular practices in this way we should receive only halfrate capitation fees

The half-rate temporary resident fee of $71 \mathrm{p}$ covers care of the patients for a threemonth period however often attention is required. The emergency treatment fee of $95 \mathrm{p}$ is for 24-hour cover only.

Temporary resident fees are one of the several items which make up the income of general practitioners, especially those serving holiday areas. It has not been suggested that any of the other items-for example, maternity fees, should be reduced if more than a certain number of patients are seen.

I believe the viability of some practices depends on temporary resident fees. If these are reduced, as suggested, this could mean cutting down medical staffing, to the detriment of both the holiday makers and the regular population.

Looking after temporary residents even for a short holiday season places considerable strain on practice resources. The work is not particularly satisfying, as one does not know the patients, much of the illness is trivial, and calls for attention come at irregular times, making smooth practice organization extremely difficult.

For 23 years full rate temporary resident 